\title{
How do readers handle incorrect information during reading?
}

\author{
DAVID N. RAPP \\ Northwestern University, Evanston, Illinois
}

\begin{abstract}
How do readers deal with information that is inconsistent with what they know? This question has typically been addressed by examining whether carefully designed texts can help readers revise inaccurate beliefs. However, texts sometimes present incorrect information that runs counter to readers' accurate knowledge. Three experiments were performed to examine how individuals process incorrect information during reading. Participants read stories describing familiar historical scenarios. These scenarios included historically accurate or inaccurate outcomes. The scenarios also included contexts that either supported accurate outcomes or utilized suspense to call into question the likelihood of those events. Overall, participants took longer to read inaccurate outcomes than to read accurate outcomes, but suspenseful contexts attenuated this difference. This pattern held even with a task that encouraged readers to consider their prior knowledge. Story contexts were particularly influential when modified to present novel scenarios. These results provide insight into the role of prior knowledge when readers encounter incorrect information, and into the consequences of such experiences.
\end{abstract}

Reading comprehension involves the integration of the unfolding text with reader knowledge. These sources of information guide the cognitive activities that underlie comprehension, including (but not limited to) the activation of meaning from long-term memory (e.g., Kintsch, 1998; McNamara \& McDaniel, 2004; Rizzella \& O'Brien, 2002), the application of prior knowledge to reason about text events and descriptions (Anderson \& Pichert, 1978; Bartlett, 1932; Bower, Black, \& Turner, 1979; Bransford \& Johnson, 1972; Schank \& Abelson, 1977), and the validation of unfolding logical arguments on the basis of beliefs about the world (e.g., Halldorson \& Singer, 2002; Lea, Mulligan, \& Walton, 2005; Singer, Halldorson, Lear, \& Andrusiak, 1992). Theoretical views of discourse comprehension detail the contributions of prior knowledge and text content in describing readers' attempts at understanding and remembering what they read (e.g., Long, Wilson, Hurley, \& Prat, 2006; McNamara \& Kintsch, 1996).

One way in which researchers have examined these contributions has been to study conditions under which readers hold incorrect beliefs, in order to evaluate whether texts might help remediate those misconceptions (e.g., Alvermann \& Hynd, 1989; Guzzetti, Snyder, Glass, \& Gamas, 1993; Kendeou, Rapp, \& van den Broek, 2003). Changing these beliefs proves difficult because individuals hold fast to their prior knowledge. But what happens when what readers know is accurate and the information they read is faulty? If texts describe situations that run counter to what readers know to be true, prior knowledge should prove useful in helping readers evaluate and discount those faulty statements. ${ }^{1}$ But even though individuals may rely on their prior knowledge when it is incorrect, in many situations they do not appear to reliably call upon their accurate prior knowledge when it would be useful. Consider that people often exhibit difficulty rejecting information that is inconsistent with what they already know, even if that information is patently false (e.g., Gilbert, Krull, \& Malone, 1990; Gilbert, Tafarodi, \& Malone, 1993).

For example, Gerrig and Prentice (1991) asked participants to read a narrative that included conversations between story characters about a variety of real-world topics. Some of the statements in those discussions were obviously false (e.g., "Most forms of mental illness are contagious") but were discussed by the characters as if they were true. The participants were later asked to verify the truth of various statements and took longer than was expected to reject patently false statements if they had been discussed in the texts as if they were true (see also Prentice, Gerrig, \& Bailis, 1997; Wheeler, Green, \& Brock, 1999). Studies of this type suggest that readers may initially accept everything they read as true and only afterward reconcile false propositions with respect to their prior knowledge. In some cases, this reconciliation is far from perfect, such that readers believe false information may have actually been derived from their prior knowledge (Marsh \& Fazio, 2006; Marsh, Meade, \& Roediger, 2003).

A challenge for successful comprehension, then, is for readers to overcome any initial propensity toward accepting everything they read as inherently true. Unfortunately, even when readers are actively encouraged to rely on what they know, they may not do so. For example, Gerrig (1989) asked participants to read story contexts that described the

D. N. Rapp, rapp@northwestern.edu 
events surrounding well-known historical situations (e.g., George Washington's becoming the first president of the United States). Control story contexts suggested that the events would play out just as expected, whereas suspenseful contexts implied that the events might not (although they had to, given real-world outcomes). Following each story, the participants were asked to verify the truth of a statement that was either consistent or inconsistent with the historical outcome. The participants took longer to verify the accuracy of historical outcomes after suspenseful contexts than after control contexts, even though the historical events had to have actually taken place. In a follow-up experiment, participants were provided with an initial statement that explicitly stated the actual historical outcome. These prior warnings failed to reduce the biasing effects of story contexts. Although both the task and the text content might have encouraged the use of prior knowledge, readers' judgments ran counter to what they ostensibly knew to be true.

These findings suggest that under a variety of conditions, readers do not rely on prior knowledge, despite theoretical views contending that such reliance is a necessary component of comprehension. However, concerns might be raised as to whether these findings are a function of the administered tasks rather than being prior knowledge failures per se. Each of these studies specifically examined the products of comprehension; that is, participants were asked to report what they knew after reading was completed through explicit judgment, recognition, and validation tests. These tasks may have led the readers to strategically focus on the experimental texts as important for completing the postreading activities, or they may have prompted context checking based on similarities between the test items and the text materials (McKoon \& Ratcliff, 1990). In either case, these tests may have encouraged readers to focus more on their recent discourse experiences than on their prior knowledge. The findings may suggest less about the degree to which prior knowledge is spontaneously relied on during reading than about the types of information readers strategically rely on after reading has been completed.

Relatedly, consider that previous work has tended to utilize tasks that specifically emphasize retrieval. Focus on these methodologies (e.g., judgment and recognition tasks) limits our understanding of what readers do as they encode inaccurate information. Marsh and Fazio (2006, Experiment 3) considered this issue by incorporating judgments directly into their reading task. Participants were asked to press one of two keys after reading each story sentence to indicate whether it contained an inaccuracy or not. Two findings from this experiment are worthy of note. First, this detection task reduced but did not eliminate participants' later use of accurate and inaccurate text information, further supporting the notion that readers rely on what they read. Second, the task led to overall slowdowns in reading times. This second issue is important because, as the authors indicate, these slowdowns were likely due to the participants' careful reading, as well as to their decisions about which key to press after each sentence. Thus, the nature of task requirements can make it a challenge to separate the processes involved as participants encode what they read from processes involved in deciding about the quality of that information (and what to do with it).

Clearly, reliance on incorrect information, whenever it occurs, is a problem. But it remains a valid question whether prior knowledge exerts an influence during the reading of incorrect information, and whether particular text conditions may moderate any such influence. To address these questions, participants in the present project were asked to read stories in which text information potentially mismatched their prior knowledge. These types of text experiences are not uncommon: Popular nonfiction bestsellers often call into question the certainty of events that nevertheless turn out as expected, in attempts to capture reader interest (Brewer, 1996; Gerrig, 1993). For example, David McCullough's 1776 (2005) provides a riveting historical narrative of the Revolutionary War. Although readers should have little doubt as to the final outcome of the familiar events described in the book, that certain knowledge is called into question with descriptions providing contextual support for counterhistorical outcomes. These types of discourse situations are examples of anomalous suspense (Gerrig, 1989), in that they set up uncertainty about outcomes that readers should be sure of otherwise. The present study used instances of anomalous suspense, and the support it can provide for inaccurate historical events, to assess readers' reliance on prior knowledge during unfolding text experiences.

For instance, readers should firmly believe that "George Washington was elected first President of the United States." However, suspense can be established by offering contextual uncertainty about such well-known events. The present experiments set up these contingencies. Consider the following story:

George Washington was a famous figure after the Revolutionary War. He was a popular choice to lead the new country. Washington, however, wanted to retire after the war. The long years as a general had left him tired and frail. Washington was eventually asked to run for President of the United States. He wrote that he would be unable to accept the nomination. People hoped that John Adams might consider running for the position.

The most likely outcome suggested by this story context is that Washington will not serve as the first president. However, readers should know that Washington will end up as commander-in-chief. This contrasts with texts in which story contexts match what readers know. Consider a more unambiguous version of this story:

George Washington was a famous figure after the Revolutionary War. He was a popular choice to lead the new country. The success of the Revolutionary War was attributed largely to Washington. Several prominent politicians asked him if he would serve as President. He discussed the position with members of his family and close friends. They were entirely 
supportive of his interest in the position. Washington agreed that he had abundant experience as a leader.

The degree to which readers rely on prior knowledge can be examined by measuring reading times for outcomes that vary in terms of historical accuracy. For instance, an outcome stating "George Washington was elected first President of the United States" is consistent with both history and the unambiguous version of the story, but it is inconsistent with the suspenseful context. In contrast, "George Washington was not elected first President of the United States" is consistent with the suspenseful context, but not with what readers should know or what the unambiguous story suggests will occur. Reading times provide a metric of readers' difficulty integrating statements into a discourse representation as texts unfold (e.g., Albrecht \& O’Brien, 1993; Cook, Halleran, \& O’Brien, 1998; Rapp, Gerrig, \& Prentice, 2001), thereby offering insight into the contributions of prior knowledge to moment-by-moment comprehension. These contributions were examined in three experiments that varied the degree to which texts provided, and supported, incorrect information.

\section{EXPERIMENT 1}

In Experiment 1, participants read both unambiguous and suspenseful expository texts. The situations described in the texts either supported or called into question actual historical events, after which readers might encounter inaccurate information. There are at least three hypotheses that articulate the potential contributions of prior knowledge and story contexts in these situations. First, readers may critically evaluate the validity of sentences as they read. If prior knowledge is utilized in this way, readers should take longer, regardless of context, to read historically inaccurate, as opposed to accurate, outcomes. Although the notion that readers critically evaluate everything they read is unlikely, some accounts have suggested that, under particular conditions, readers validate what they read with respect to prior knowledge (e.g., Singer, 2006). Well-known causal or bridging relations, which are key components of historical descriptions, encourage such validation. Thus, the present materials might invoke validation during reading.

In contrast, readers may be influenced, to a large degree, by unfolding story contexts during comprehension. This hypothesis is consistent with previous work showing that, for postreading tasks, readers defer to text information even when they should know that it is incorrect (e.g., Gerrig \& Prentice, 1991; Marsh et al., 2003). Support for this hypothesis would be obtained if unambiguous contexts led to longer reading times for historically inaccurate outcomes than for historically accurate outcomes and, in a complementary way, suspenseful contexts led to longer reading times for historically accurate outcomes than for historically inaccurate outcomes. In other words, readers may be biased by story contexts in a manner that leads to difficulty integrating outcomes that run counter to those contexts, regardless of their inherent historical accuracy.
A third hypothesis suggests that the contributions of prior knowledge and story contexts are more nuanced than the predictions offered above. Interactions between story contexts and outcomes would help identify the particular conditions under which readers are more or less likely to be influenced by what they know and biased by what stories tell them. These types of interactions have proven informative for describing and explaining a variety of reader activities relevant to semantic activation and memory updating (e.g., Cook \& Guéraud, 2005; Cook \& Myers, 2004; Garrod \& Terras, 2000; Kendeou \& van den Broek, 2007; Kintsch, 1988; Morris, 1994). For example, previous work has shown that although readers build expectations for story events on the basis of prior knowledge, these expectations are malleable as a function of unfolding contexts (Rapp \& Gerrig, 2002, 2006). In an analogous way, prior knowledge may guide beliefs about what will happen in familiar scenarios, but expectations for those events may show flexibility as a function of suspenseful contexts. In line with this view, participants overall should take longer to read historically inaccurate outcomes than to read historically accurate outcomes, but this effect should be reduced when suspenseful stories support those inaccurate outcomes. This interaction would reveal both the impact and, to some degree the limits, of prior knowledge during reading.

\section{Method}

Participants. Sixty-one University of Minnesota undergraduates participated in this study for course credit. The data from 1 participant were eliminated for failure to follow instructions. All the participants were native speakers of English.

Apparatus. Three Pentium PCs running SuperLab software recorded participant responses. The participants sat in front of a Dell color monitor with their hands on the keyboard and used buttons on the keyboard to provide their responses. Sentences were presented in the center of the screen in standard upper- and lowercase type. SuperLab software recorded the participants' responses, including the keys pressed during the task and reading latencies for each sentence. Latencies were recorded as the interval (in milliseconds) between a sentence's onscreen presentation and a participant's press of the "Next" key.

Materials. The stories used in this experiment were based on materials from Gerrig (1989), with modifications as described below. Gerrig's (1989) study served as an existence proof for the consequences of anomalous suspense with respect to offline reading activity. Each of the 32 stories in that experiment included a topic that was well known to readers, and each story included only a single outcome that was either consistent or inconsistent with that knowledge. Sixteen topics and their accompanying outcomes from the Gerrig (1989) stimuli were used, with a new, second outcome written for each story. In addition, 16 new topics and outcomes were written as replacements to the original set in order to make the stories more contemporary for the present sample of participants (e.g., a story about Michael Jackson's possibly being injured during a Pepsi commercial was replaced with a story about Lance Armstrong's cancer struggle). Pairs of outcomes were prepared in such a way that each story included an outcome that was historically accurate with respect to that story topic and an outcome that was historically inaccurate with the topic. Half of the historically accurate outcomes included the word not or never (e.g., "Elvis Presley was not murdered at his Graceland mansion."), and half did not (e.g., "Charles Lindbergh was the first solo pilot to cross the Atlantic."); similarly, 
Table 1

Sample Stories and Outcomes From Experiments 1 and 2

[Introduction]

In 1865, a Frenchman named Laboulaye wished to honor democratic progress in the U.S.

$\mathrm{He}$, along with artist Auguste Bartholdi, conceptualized a giant sculpture.

[Suspenseful context]

Their 'Statue of Liberty' would require extensive fundraising work.

Raising the exorbitant funds for the statue proved an enormous challenge.

Because of financial difficulties France could not afford to make a gift of the statue.

Fundraising was arduous and plans quickly fell behind schedule.

Because of these problems, completion of the statue seemed doomed to failure.

[Unambiguous context]

Their 'Statue of Liberty' would require extensive fundraising work.

They organized a public lottery to generate support for the sculpture.

American businessmen also contributed money to build the statue's base.

Despite falling behind schedule, the statue was completed.

The statue's base was finished as well and ready for mounting.

[Accurate outcome]

The Statue of Liberty was delivered from France to the United States.

[Inaccurate outcome]

The Statue of Liberty was not delivered from France to the United States.

[Coda]

The intended site of the statue was a port in New York harbor.

This location functioned as the first stop for many immigrants coming to the U.S.

QUESTION: Did Bartholdi come up with the idea of donating the statue on his own?

NO

[Introduction]

L. Frank Baum was the author of the book, "The Wizard of Oz."

The popularity of the book led MGM Studios to purchase the movie rights.

[Suspenseful context]

To ensure the movie's success, MGM wanted a big star in the lead role of Dorothy.

Judy Garland made the list of qualified candidates.

However MGM wanted Shirley Temple to star in the film.

Shirley Temple was the biggest child star at the time.

Temple's agent quickly negotiated and a contract was drafted.

[Unambiguous context]

MGM wanted a young woman with charisma in the starring role of Dorothy.

Judy Garland was a far better candidate than the much younger Shirley Temple.

During Garland's tryout, she delivered a wonderful rendition of "Over the Rainbow."

The director, producer, and studio were all enamored with her performance.

Now all that was left was casting for the Tinman, Scarecrow, and Cowardly Lion.

[Accurate outcome]

Shirley Temple did not star in the movie "The Wizard of Oz."

[Inaccurate outcome]

Shirley Temple starred in the movie "The Wizard of Oz."

[Coda]

The Wizard of Oz ended up both a commercial and critical success.

It was also one of the first movies to appear in full color.

QUESTION: Did W. Somerset Maugham write "The Wizard of Oz"? NO

half of the historically inaccurate outcomes included the word not or never (e.g., "The United States did not drop an atomic bomb on Japan."), and half did not (e.g., "The Titanic withstood the damage from the iceberg collision."). Overall, the outcomes were equated for length: Historically accurate outcomes contained, on average, 10.31 words $(S D=1.75)$, and historically inaccurate outcomes contained, on average, 10.16 words $(S D=1.92)$, a nonsignificant difference $[t(31)=0.587, p<1]$. When measured by number of characters (including spaces and punctuation), historically accurate outcomes contained, on average, 60 characters $(S D=9.60)$, and historically inaccurate outcomes contained, on average, 59.1 characters $(S D=$ $10.10)$, also a nonsignificant difference $[t(31)=0.958, p<1] .^{2}$

Thirty-two story contexts were written around these topic/ outcome frames to support either a historically accurate outcome (i.e., unambiguous contexts) or a historically inaccurate outcome (i.e., suspenseful contexts). It should be noted that the suspenseful contexts did not state with certainty that historical events would not occur or were impossible; rather, they called into question the certainty of those events. Each story was 10 sentences long, including a single outcome (see Table 1 for examples). The first 2 sentences of the unambiguous and suspenseful versions of a story were identical, providing an introduction to the topic and its historical significance. The next 5 sentences (Sentences 3-7) of the stories differed in content, depending on context condition-containing, on average, 60 words $(S D=5.67)$ for suspenseful contexts and 56.43 words $(S D=$ $4.77)$ for unambiguous contexts $[t(31)=3.61, p<.01]$ and, on average, 355.59 characters $(S D=27.19)$ for suspenseful contexts and 340.87 characters $(S D=28.11)$ for unambiguous contexts $[t(31)=$ 
$2.44, p<.05]$. The 8 th sentence of the story provided one of the two outcomes, depending on outcome condition. The final 2 sentences of the story concluded the narrative, offering a coda for the historical topic. This coda contained a general conclusion for the story that did not elaborate on the fact potentially called into question and maintained historical accuracy. On average, the stories contained 115.84 words $(S D=9.01)$, calculated as 684.08 characters per story $(S D=$ 43.57), across all four story types. A single comprehension question was also written for each story, asking about general elements of the stories but not about the particular facts potentially called into question by the suspenseful contexts.

Five practice stories and questions were also written to provide training for the task. These practice stories had a structure similar to that of the experimental items but did not describe historical events. There was only one version of each practice item.

Design. There were four versions of each of the 32 stories, as a function of story context (unambiguous vs. suspenseful) and outcome sentence (historically accurate vs. historically inaccurate). Using a Latin square, four lists were constructed, with each story appearing in a different version on each list, to implement a repeated measures design. Each participant read one version of each story, with stories in a list presented in a different random order for each participant. Comprehension questions were counterbalanced so each list contained 16 questions requiring yes and 16 requiring no responses.

Procedure. The participants began with the practice stories in order to become familiar with the task and keyboard controls. The stories were presented one complete sentence at a time on the computer screen. The participants were asked to read each story at their own pace. ${ }^{3}$ Each story began with the words "Press NEXT for the next story." The participants pressed the "A" key, labeled "Next," to begin the story. After reading a sentence, the participants pressed the "Next" key to advance to the next sentence. After reading the final sentence of a story, a beep sounded from the computer, and a prompt read “*** THINK OF A TITLE FOR THE STORY ***” (cf. Rapp \& Gerrig, 2002; Rapp et al., 2001). This task was included in order to ensure that the participants would pay appropriate attention while reading each story (see Rapp \& Kendeou, 2007, for a discussion of this task). The participants were never asked to provide the title. After participants pressed the "Next" key (to signal that they had thought of a title), another beep followed, and the string “***** QUESTION *****" was displayed. This string was replaced after $1,000 \mathrm{msec}$ by a comprehension question, with no time limit for a response. The participants pressed either the "J" key, labeled "Yes," or the "K" key, labeled "No," to respond.

Norming study. Prior to analysis, the 32 items were submitted to a norming study intended to evaluate participants' familiarity with the facts described in the stories. Fifty University of Minnesota undergraduates were asked to read only the historically accurate and inaccurate outcome statements for each item and to indicate which of the two statements (labeled A or B) in the pair was true. This procedure was conducted via computer, with five or six sets of pairs presented on the screen at a time. The participants were instructed to use the mouse to "select the letter of the statement from the pair that you believe is true," with accurate and inaccurate statements randomly presented as Statement A or B in each pairing. After making their selections, participants clicked on a "Next" button with the mouse to proceed to the next screen of pairings.

To determine familiarity with the items, a cutoff of $70 \%$ of participants correctly selecting a true statement was used to distinguish familiar from unfamiliar facts; a similar cutoff had been implemented by Marsh et al. (2003) and Marsh and Fazio (2006) as an indicator of high familiarity with facts from the Nelson and Narens (1980) general knowledge norms. The data revealed that the participants were relatively unfamiliar with only 2 of the 32 items. Of the 30 familiar items, on average, $90 \%$ of the participants answered them correctly, with a median score of $91 \%$; the modal participants' agreement score for the familiar items was $100 \%$. All results to be reported were obtained from these 30 highly familiar facts, omitting the 2 unfamiliar items from the analyses.

\section{Results and Discussion}

To account for the fact that the sentences in the texts were not all of a single uniform length, the data were transformed, using a procedure suggested by Trueswell, Tanenhaus, and Garnsey (1994) and Ferreira and Clifton (1986). This procedure is intended to adjust for differences in text or string length. Each participant's reading times were predicted using a linear regression equation computed with sentence length (indexed by characters, including spaces and punctuation) as an independent variable and that participant's sentence reading times as a dependent variable. The predicted reading time was then subtracted from the participant's actual reading times, and the residuals were submitted to statistical analyses. (For ease of presentation, all mean reading times provided in the tables and in the Results sections refer to raw scores. Note that the analyses based on untransformed reading times were largely similar to the residual analyses.)

All the analyses in this study were conducted with both participants $\left(F_{1}\right)$ and items $\left(F_{2}\right)$ as random variables. Reading times falling more than three standard deviations above the mean for each participant were eliminated, resulting in a loss of $2.06 \%$ of the data. The participants, on average, correctly answered $84.1 \%$ of the comprehension questions (by condition: unambiguous-historically accurate, $84.4 \%$; unambiguous-historically inaccurate, $85.7 \%$; suspenseful-historically accurate, $82.4 \%$; suspensefulhistorically inaccurate, $83.7 \%$ ). Table 2 presents the outcome reading times obtained in Experiment 1.

Readers appeared to take note of historical discrepancies: Overall, participants took $552 \mathrm{msec}$ longer to read historically inaccurate outcomes than to read accurate outcomes $\left[F_{1}(1,59)=129.146, M S_{\mathrm{e}}=154,757, p<.001\right.$; $\left.F_{2}(1,29)=59.101, M S_{\mathrm{e}}=166,872, p<.001\right]$. This main effect, though, was qualified by a significant interaction between context and outcome $\left[F_{1}(1,59)=7.152, M S_{\mathrm{e}}=\right.$

Iable 2

Mean Reading Times (in Milliseconds, With Standard Deviations) for Outcome Sentences in Experiments 1, 2, and 3

\begin{tabular}{|c|c|c|c|c|c|}
\hline \multirow[b]{2}{*}{ Context } & \multicolumn{2}{|c|}{$\begin{array}{l}\text { Historically } \\
\text { Accurate } \\
\text { Outcome }\end{array}$} & \multicolumn{2}{|c|}{$\begin{array}{c}\text { Historically } \\
\text { Inaccurate } \\
\text { Outcome } \\
\end{array}$} & \multirow{2}{*}{$\begin{array}{c}\text { Mean } \\
\text { Difference }\end{array}$} \\
\hline & $M$ & $\overline{S D}$ & $M$ & $S D$ & \\
\hline \multicolumn{6}{|c|}{ Experiment 1} \\
\hline Suspenseful & 2,751 & 734 & 3,161 & 622 & -410 \\
\hline $\begin{array}{l}\text { Unambiguous } \\
\text { Mean difference }\end{array}$ & $\begin{array}{l}2,650 \\
+101\end{array}$ & 678 & $\begin{array}{l}3,343 \\
-182\end{array}$ & 842 & -693 \\
\hline \multicolumn{6}{|c|}{ Experiment 2} \\
\hline $\begin{array}{l}\text { Suspenseful } \\
\text { Unambiguous } \\
\text { Mean difference }\end{array}$ & $\begin{array}{l}2,622 \\
2,520 \\
+102\end{array}$ & $\begin{array}{l}580 \\
495\end{array}$ & $\begin{array}{r}3,177 \\
3,275 \\
-98\end{array}$ & $\begin{array}{l}729 \\
837\end{array}$ & $\begin{array}{l}-555 \\
-755\end{array}$ \\
\hline \multicolumn{6}{|c|}{ Experiment 3} \\
\hline $\begin{array}{l}\text { "Suspenseful" } \\
\text { "Unambiguous" } \\
\text { Mean difference }\end{array}$ & $\begin{array}{l}3,175 \\
3,056 \\
+119\end{array}$ & $\begin{array}{l}800 \\
805\end{array}$ & $\begin{array}{l}3,220 \\
3,468 \\
-248\end{array}$ & $\begin{array}{l}803 \\
887\end{array}$ & $\begin{array}{r}-45 \\
-412\end{array}$ \\
\hline
\end{tabular}

Note-For Experiment 3, the terms "unambiguous," "suspenseful," and "historically accurate/inaccurate" were retained because items were modified from Experiments 1 and 2. However, it is unlikely that the readers held a priori expectations for these modified stories. 
$177,197, p<.01 ; F_{2}(1,29)=8.347, M S_{\mathrm{e}}=66,948, p<$ $.01]$, but no main effect of story context (all $F_{\mathrm{s}}<1$ ). Planned comparisons revealed that participants took longer to read inaccurate outcomes than to read accurate outcomes following unambiguous contexts $\left[F_{1}(1,59)=\right.$ $80.982, M S_{\mathrm{e}}=386,738, p<.001 ; F_{2}(1,29)=62.651$, $\left.M S_{\mathrm{e}}=241,274, p<.001\right]$ and following suspenseful contexts $\left[F_{1}(1,59)=40.366, M S_{\mathrm{e}}=277,169, p<.001\right.$; $\left.F_{2}(1,29)=25.296, M S_{\mathrm{e}}=226,365, p<.001\right]$, although this difference was larger following unambiguous contexts (mean difference $=693 \mathrm{msec}$ ) than following suspenseful contexts (mean difference $=410 \mathrm{msec}$ ). Additional planned comparisons across outcome type also suggested that participants' expectations for outcomes were pushed in potentially inappropriate directions when story contexts mismatched prior knowledge. Participants took $182 \mathrm{msec}$ longer to read historically inaccurate outcomes following unambiguous contexts, as compared with suspenseful contexts $\left[F_{1}(1,59)=5.851, M S_{\mathrm{e}}=327,989, p<.05\right.$; $\left.F_{2}(1,29)=5.288, M S_{\mathrm{e}}=172,375, p<.05\right]$, whereas in contrast, they took $101 \mathrm{msec}$ longer to read historically accurate outcomes following suspenseful contexts than following unambiguous contexts [marginal by participants only; $F_{1}(1,59)=2.983, M S_{\mathrm{e}}=251,482, p=.089$; $\left.F_{2}(1,29)=2.307, p>.1\right]$.

How quickly do readers overcome the potentially biasing influence of story contexts that run counter to what they know? Although previous studies have shown an effect of inconsistent information on postreading memory tasks (which, again, may be a function of task-invoked retrieval strategies), they have not provided insight as to how readers deal with false information as reading continues. Analyses of reading times for the sentence immediately following an outcome can indicate whether the interaction effect "spilled over" to the processing of subsequent sentences (e.g., Albrecht \& O’Brien, 1993; Cook \& Guéraud, 2005). Recall that the sentences that immediately followed outcomes generally summarized the historical events and were always historically accurate (although, again, the immediately preceding outcome may not have been accurate). They were also identical across story contexts [on average, this ninth sentence contained 12.18 words $(S D=$ $2.19)$, also calculated as 68.97 characters $(S D=10.09)]$. As is shown in Table 3, overall participants took $147 \mathrm{msec}$ longer to read these sentences following historically inaccurate outcomes than following accurate outcomes $\left[F_{1}(1,59)=7.562, M S_{\mathrm{e}}=180,385, p<.01 ; F_{2}(1,29)=\right.$ $\left.14.294, M S_{\mathrm{e}}=50,478, p<.001\right]$. There was no longer an interaction with context type and, as before, no main effect of story context (all $F$ 's $<1$ ). Participants exhibited a general slowdown when the preceding outcome sentence mismatched the historical event, regardless of the supporting context.

These results demonstrate that, overall, prior knowledge guided participants' expectations for historical events, but that these expectations were also biased by the suspenseful descriptions provided in texts. It might be considered quite surprising that story contexts exerted any influence whatsoever; recall that the experimental stories described events that should be quite familiar, given their historical significance. Consistent with this notion, the interaction effect was relatively short-lived. By the immediately following sentence, readers' processing was largely a function of the historical accuracy of the outcome they read, and not the potentially mismatching contexts of the stories. It is unclear whether these spillover results were due to a local coherence break (e.g., the spillover sentence was in line with actual historical events, whereas the historically inaccurate outcome was not), some form of reconciliation or wrapping-up process with respect to the information provided by the story contexts, or a combination of the two. Regardless, the interaction and spillover effects indicate that prior knowledge influenced moment-by-moment comprehension, even when readers encountered inaccurate information endorsed by story contexts.

In this experiment, the participants were at no point explicitly encouraged to rely on prior knowledge for comprehension. Thus, these findings might actually underestimate the degree to which readers can strategically inoculate themselves from the effects of suspenseful or inaccurate story contexts. This issue was investigated in Experiment 2.

\section{EXPERIMENT 2}

Readers sometimes fail to adequately rely on prior knowledge because they do not necessarily know that it will prove beneficial for comprehending a particular text (e.g., Chiesi, Spilich, \& Voss, 1979; Pearson, Hansen, \& Gordon, 1979; Spires \& Donley, 1998). Thus, readers may be more likely to notice inaccurate information when they are made aware of their knowledge with respect to the topic. Some educational interventions specifically target the activation of prior knowledge to encourage careful evaluation of reading materials and enhance learning

Table 3

Mean Reading Times (in Milliseconds, With Standard Deviations) for Spillover Sentences in Experiments 1, 2, and 3

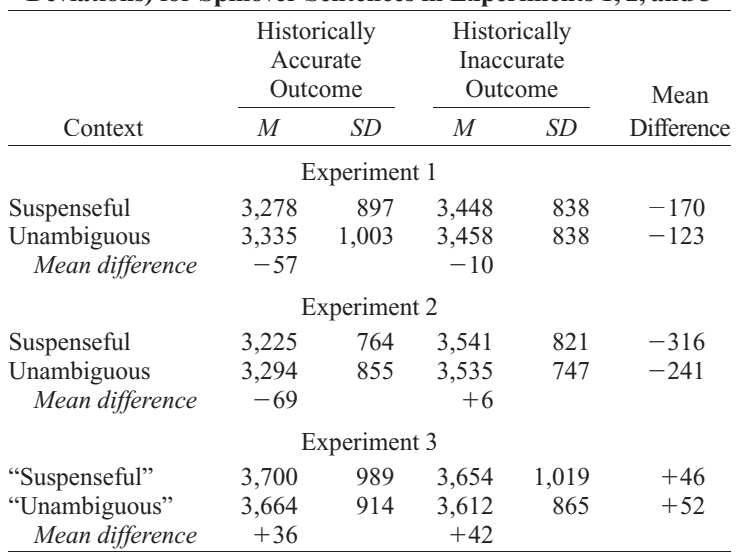

Note-For Experiment 3, the terms "unambiguous," "suspenseful," and "historically accurate/inaccurate" were retained because items were modified from Experiments 1 and 2. However, it is unlikely that the readers held a priori expectations for these modified stories. 
from texts (see Guzzetti et al., 1993, for a review). These interventions often utilize preactivation tasks that require students to indicate what they know about a particular topic before a learning experience (see, e.g., Alvermann \& Hague, 1989). An analogous methodology was used in Experiment 2. Immediately preceding each story, the participants were asked to write down two facts related to the story topic. This preactivation task was designed to prompt readers to rely on their prior knowledge to read the texts. Note that this task was intended to encourage participants' reliance on that knowledge but in no way ensured that they would do so. Thus, Experiment 2 tested whether the effects of suspenseful contexts might be reduced when readers were required to reflect on what they knew prior to reading.

If the preactivation activity encourages increased reliance on prior knowledge during reading, participants should continue to take longer to read historically inaccurate outcomes than to read accurate outcomes, but with little influence of story contexts - a main effect of story outcome. If, however, this preactivation activity does not lead readers to rely to a greater degree on prior knowledge than previously observed, the results should resemble those of Experiment 1-an overall main effect of outcome, moderated by an interaction with story context. This would suggest that although prior knowledge matters during reading, preactivating that knowledge before reading does not reduce the immediate biasing influence of story contexts.

\section{Method}

Participants. Sixty-two University of Minnesota undergraduates participated in this study for course credit. Two participants' data were eliminated for failure to follow instructions. All participants were native speakers of English.

Apparatus. The apparatus was identical to that in Experiment 1, except that the participants were also provided with an answer booklet and a pen to complete the preactivation activity.

Materials. The same experimental stories as those in Experiment 1 were used, with only two practice stories preceding the task. A nine-page booklet was prepared for each participant. The booklet provided space for the participants to write two facts about each story, with four stories per page (except for the first page, which provided space only for writing facts about the two practice stories), numbered from 1 to 32 .

Design. The design was identical to that in Experiment 1.

Procedure. The procedure was identical to that in Experiment 1, with the following modifications. After participants pressed the "Next" key to begin a story, a prompt read, "Write two different facts that each describe something you know about $X$," with $X$ replaced with the topic of the story (e.g., George Washington, the Wright brothers, the Pilgrims). Participants wrote down their two facts in the booklet, with no time limit for producing facts. Then they placed their hands back on the keyboard and pressed the "Next" key to begin the story.

Preactivation fact coding. Participants' productions were coded as related (e.g., "George Washington was the 1st president.") or unrelated (e.g., George Washington "made a meal entirely out of peanuts," likely a confusion with George Washington Carver) to the fact request. If coded as related, the production was further coded as either directly relevant to the story outcome (e.g., "He was the first president of the U.S.") or generally relevant to the topic (e.g., "His teeth were made of wood."). A randomly selected subset (20\%) of the participants' productions was scored by two coders blind to condition. There was $95 \%$ agreement on their codings, with differences resolved through discussion. The remaining set of productions was scored by one coder.

\section{Results and Discussion}

As in Experiment 1, all analyses omitted the two items identified as unfamiliar on the basis of the norming results, and all analyses were conducted on residual reading times. Reading times falling more than three standard deviations above the mean for each participant were eliminated, resulting in a loss of $1.64 \%$ of the data. The participants, on average, correctly answered $87.4 \%$ of the comprehension questions (by condition: unambiguous-historically accurate, $89.6 \%$; unambiguous-historically inaccurate, $88.2 \%$; suspenseful-historically accurate, $85.1 \%$; suspensefulhistorically inaccurate, $86.7 \%$ ). In the preactivation task, the participants left out facts for fewer than $1 \%$ of the items, and $5.61 \%$ of all facts provided were unrelated to the topics. Overall, $94.39 \%$ of the provided facts were relevant in some general way to the stories, and $30.67 \%$ of the provided facts were directly relevant to the actual historical outcomes manipulated in the task. The latter percentage is encouraging with respect to the purpose of the experiment; participants provided only two facts for each story, and yet almost a third of the provided responses were related to the particular fact potentially called into question. Consider that the request "Write two different facts that each describe something you know about George Washington" could be answered in any number of relevant ways (e.g., he had wooden teeth, he was a general in the Revolutionary War, he wore a powdered wig, etc.), yet a relatively large percentage of responses corresponded directly with the eventual outcomes of the texts (e.g., he was the first president). Table 2 presents the outcome reading times obtained in Experiment 2.

Participants overall took $655 \mathrm{msec}$ longer to read historically inaccurate outcomes than to read accurate outcomes $\left[F_{1}(1,59)=132.687, M S_{\mathrm{e}}=219,019, p<.001\right.$; $\left.F_{2}(1,29)=60.818, M S_{\mathrm{e}}=231,806, p<.001\right]$. This main effect was qualified by a significant interaction between context and outcome $\left[F_{1}(1,59)=6.854, M S_{\mathrm{e}}=132,495\right.$, $\left.p<.05 ; F_{2}(1,29)=4.298, M S_{\mathrm{e}}=96,179, p<.05\right]$, with no main effect of story context (all $F$ 's $<1$ ). Planned comparisons revealed that participants took longer to read inaccurate outcomes than to read accurate outcomes following unambiguous contexts $\left[F_{1}(1,59)=110.360, M S_{\mathrm{e}}=\right.$ $364,657, p<.001 ; F_{2}(1,29)=55.988, M S_{\mathrm{e}}=345,420$, $p<.001]$ and following suspenseful contexts $\left[F_{1}(1,59)=\right.$ $58.204, M S_{\mathrm{e}}=338,371, p<.001 ; F_{2}(1,29)=31.181$, $\left.M S_{\mathrm{e}}=310,549, p<.001\right]$, although this difference was larger following unambiguous contexts (mean difference $=755 \mathrm{msec}$ ) than following suspenseful contexts (mean difference $=555 \mathrm{msec}$ ). Two final planned comparisons suggested that story contexts influenced outcome expectations to some degree even with the preactivation task. Participants took $98 \mathrm{msec}$ longer to read historically inaccurate outcomes following unambiguous contexts as compared with suspenseful contexts [significant by participants only; $F_{1}(1,59)=11.256, M S_{\mathrm{e}}=641,920, p<$ $\left..001 ; F_{2}(1,29)=1.956, p>.1\right]$ and $102 \mathrm{msec}$ longer to 
read accurate outcomes following suspenseful contexts than following unambiguous contexts [significant by participants only; $F_{1}(1,59)=6.032, M S_{\mathrm{e}}=160,598, p<.05$; $\left.F_{2}(1,29)=2.395, p>.1\right]$. Overall, the results resembled those obtained in Experiment 1.4

A spillover analysis examined whether these effects extended to the sentence immediately following the outcome (see Table 3). Overall the participants took $279 \mathrm{msec}$ longer to read these sentences following historically inaccurate outcomes than following accurate outcomes $\left[F_{1}(1,59)=22.489, M S_{\mathrm{e}}=211,447, p<.001\right.$; $\left.F_{2}(1,29)=18.913, M S_{\mathrm{e}}=127,456, p<.001\right]$. As in Experiment 1, there was no interaction or main effect of story context (all $\left.F_{\mathrm{s}}<1\right)$. The participants again took longer to read spillover sentences following a historically inaccurate outcome, regardless of the context supporting that outcome.

Consistent with Experiment 1, overall reading slowdowns were observed when outcomes mismatched what the readers knew. But importantly, the participants' reading times were influenced by suspenseful contexts. The preactivation task, intended to help readers activate their prior knowledge, did not eliminate the effects of suspense. And, as before, the effects of suspense were relatively short-lived, as indicated by the spillover analysis. Inaccurate information did not completely override readers' reliance on prior knowledge as the texts unfolded.

\section{EXPERIMENT 3}

The previous two experiments examined conditions in which prior knowledge could potentially prove useful for comprehending texts containing inaccurate information. To further assess the influence of prior knowledge on comprehension, it is worth examining conditions in which it might not be as useful. In Experiment 3, the participants read modified versions of the stories that maintained similar plots but renamed the characters and situations. With this change, readers should have been relatively unaware that the stories were analogous to well-known historical events. For instance, consider a revised version of our unambiguous George Washington story:

Steven Somerville was a famous figure after the organization's merger. He was a popular choice to lead the new company. The success of the organization's merger was attributed largely to Somerville. Several prominent chairmen asked him if he would serve as president. He discussed the position with members of his family and close friends. They were entirely supportive of his interest in the position. Somerville agreed that he had abundant experience as a leader.

This story maintains the same general set of events as that described in the Washington story. But readers, being unfamiliar with the situation and character, should be unlikely to rely on what they know about particular historical events to generate expectations for story outcomes. This is not to say that readers could not rely on prior knowledge to consider the likelihood of Somerville's becoming president; rather, it suggests that, given readers' resistance to spontaneously engaging in analogical reasoning (e.g., Gick \& Holyoak, 1983) and their lack of familiarity with these new characters and events, they should not rely on their knowledge of George Washington to resolve this outcome. Sulin and Dooling (1974) set up similar contingencies to examine whether readers' prior knowledge might lead to confusion about story events, as measured in offline recognition tasks. In contrast, the present experiment assessed the degree to which readers' online processing of unfamiliar stories resembled their processing of familiar events.

Participants read these stories in either "unambiguous" (supporting a particular outcome) or "suspenseful" contexts (questioning the certainty of an outcome). Note that "suspenseful" and "unambiguous" contexts here are based on their counterpart stories in the previous experiments, given that readers could not have held a priori expectations for these revised stories. Each story ended with an "accurate" or an "inaccurate" outcome; again, the "accuracy" of these outcomes was relevant only with respect to versions of the stories that described historical events with historically accurate or inaccurate outcomes.

Given that participants would be unlikely to rely on fact-based prior knowledge, it was expected they would rely predominantly on the information provided by the story contexts. This presents a situation in which story contexts should exert a considerable impact on readers' processing. Thus, an interaction was predicted such that (1) the participants would take longer to read "inaccurate" versus "accurate" outcomes following "unambiguous" contexts, since "unambiguous" contexts supported those "accurate" outcomes, and (2) following "suspenseful" contexts, participants' reading times for both outcome types would be similar given the lack of information to be garnered from prior knowledge concerning the specific viability of either outcome. In some sense, this predicted interaction would resemble the interactions obtained earlier, although the differing effects following "suspenseful" contexts would further delineate the contributions of prior knowledge in true instances of anomalous suspense (i.e., in Experiments 1 and 2).

\section{Method}

Participants. Sixty-one University of Minnesota undergraduates participated in this study for course credit. The data from 1 participant were eliminated for failure to follow instructions. All the participants were native speakers of English.

Apparatus. The apparatus was identical to that in Experiment 1.

Materials. The experimental stories from Experiment 1 were modified to maintain their original plot structures but to include new situations and characters (see Table 4 for examples). The names of characters and events from the stories were changed to unfamiliar tokens (e.g., Elvis Presley became Craig Samuels; the Titanic ocean liner became the Royal, a luxury plane; Johnny Carson and the Tonight Show became Howard Tenny and the Ha-Ha Hour), with only slight modification to the length of the stories. On average, the stories contained 116.52 words $(S D=9.02)$, calculated as 700.58 characters per story $(S D=46.99)$, across all four story types. The outcomes were also changed to reflect these story modifications but were still equated overall for length: "Accurate" outcomes contained, on average, 10.44 words $(S D=1.68)$, and "inaccurate" outcomes contained, 
Table 4

Sample Stories and Outcomes From Experiment 3

[Introduction]

In 1947, a Russian named Petrovich wished to honor political progress in the Chinese Republic.

$\mathrm{He}$, along with artist Norbert Gershstoy, conceptualized a giant sculpture.

["Suspenseful" context]

Their 'Pillar of Camaraderie' would require extensive fundraising work.

Raising the exorbitant funds for the statue proved an enormous challenge.

Because of financial difficulties Russia could not afford to make a gift of the statue.

Fundraising was arduous and plans quickly fell behind schedule.

Because of these problems, completion of the statue seemed doomed to failure.

["Unambiguous" context]

Their 'Pillar of Camaraderie' would require extensive fundraising work.

They organized a public lottery to generate support for the sculpture.

Russian financiers also contributed money to build the statue's base.

Despite falling behind schedule, the pillar was completed.

The pillar's base was finished as well and ready for mounting.

["Accurate" outcome]

The Pillar of Camaraderie was delivered from Russia to the Chinese Republic.

["Inaccurate" outcome]

The Pillar of Camaraderie was not delivered from Russia to the Chinese Republic.

[Coda]

The intended site of the statue was a port in the Dandong municipality.

This location functioned as the first stop for many refugees coming to China.

QUESTION: Did Petrovich come up with the idea of donating the pillar on his own? NO

[Introduction]

Lewis T. Bart was the author of the book, "You Drink to Me."

The popularity of the book led HDS Films to purchase the movie rights.

["Suspenseful" context]

To ensure the movie's success, HDS wanted a big star in the lead role of Tabitha.

Bebe Daniels made the list of qualified candidates.

However HDS wanted Corrine Kenyon to star in the film.

Corrine Kenyon was the biggest female star at the time.

Kenyon's agent quickly negotiated and a contract was drafted.

["Unambiguous" context]

HDS wanted a young woman with charisma in the starring role of Tabitha.

Bebe Daniels was a far better candidate than the much younger Corrine Kenyon.

During Daniel's tryout, she delivered a wonderful rendition of "My Dear Heart."

The director, producer, and studio were all enamored with her performance.

Now all that was left was casting for the neighbor, bartender, and abusive husband.

["Accurate" outcome]

Corrine Kenyon did not star in the movie "You Drink to Me."

["Inaccurate" outcome]

Corrine Kenyon starred in the movie "You Drink to Me."

[Coda]

"You Drink to Me" ended up both a commercial and critical success.

It was also one of the first movies to run with orchestral music.

QUESTION: Did M. Wetterly Gorshin write "You Drink to Me"? NO

on average, 10.28 words $(S D=2.05)$, a nonsignificant difference $[t(31)=0.587, p<1]$. When measured by number of characters (including spaces and punctuation), "accurate" outcomes contained, on average, 61.28 characters $(S D=9.92)$, and "inaccurate" outcomes contained, on average, 60.38 characters $(S D=10.65)$, also a nonsignificant difference $[t(31)=0.920, p<1]$.

Design. The design was identical to that in Experiment 1.

Procedure. The procedure was identical to that in Experiment 1.

\section{Results and Discussion}

To maintain consistency with the earlier analyses, the two modified items based on previously omitted facts were similarly omitted from these analyses; in addition, as in Experiment 1, all the analyses were conducted on residuals. Reading times falling more than three standard deviations above the mean for each participant were eliminated, resulting in a loss of $2.63 \%$ of the data. The participants, on average, correctly answered $80.7 \%$ of the comprehension questions (by condition: "unambiguoushistorically accurate," 78.9\%; "unambiguous-historically inaccurate," 81.9\%; "suspenseful-historically accurate," $80.6 \%$; "suspenseful-historically inaccurate," $81.2 \%$ ). As a manipulation check as to whether the participants had noticed the similarity of these stories to their historical analogues, at the conclusion of the experiment, each participant was asked whether any of the stories seemed familiar. None of the participants spontaneously reported 
these story situations as resembling historical events. Table 2 presents outcome reading times obtained in Experiment 3.

The participants took $229 \mathrm{msec}$ longer to read "inaccurate" outcomes than to read "accurate" outcomes $\left[F_{1}(1,59)=28.243, M S_{\mathrm{e}}=132,738, p<.001 ; F_{2}(1,29)=\right.$ $\left.15.901, M S_{\mathrm{e}}=119,552, p<.001\right]$. This main effect was qualified by a significant interaction between context and outcome $\left[F_{1}(1,59)=9.347, M S_{\mathrm{e}}=191,355, p<.005\right.$; $\left.F_{2}(1,29)=11.153, M S_{\mathrm{e}}=80,611, p<.005\right]$, with no main effect of story context (all $F_{\mathrm{s}}<2.17$ ). Although participants took longer to read "inaccurate" outcomes than to read "accurate" outcomes across both types of story contexts, this effect was specifically observed following "unambiguous" contexts [mean difference = $412 \mathrm{msec} ; F_{1}(1,59)=26.470, M S_{\mathrm{e}}=404,855, p<.001$; $\left.F_{2}(1,29)=17.940, M S_{\mathrm{e}}=301,822, p<.001\right]$, but not following "suspenseful" contexts (mean difference $=$ 45 msec; both $\left.F_{\mathrm{s}}<1.9\right)$. Planned comparisons further defined these effects: Participants took $248 \mathrm{msec}$ longer to read "inaccurate" outcomes following "unambiguous" contexts as compared with "suspenseful" contexts $\left[F_{1}(1,59)=8.650, M S_{\mathrm{e}}=394,251, p<.005 ; F_{2}(1,29)=\right.$ $\left.9.528, M S_{\mathrm{e}}=187,770, p<.005\right]$, and $119 \mathrm{msec}$ longer to read "accurate" outcomes following "suspenseful" contexts than following "unambiguous" contexts [marginal by participants only; $F_{1}(1,59)=2.904, M S_{\mathrm{e}}=394,251$, $\left.p=.094 ; F_{2}(1,31)=2.757, p>.1\right]$. Finally, the spillover analysis showed no main effects or interaction (all $F_{\mathrm{s}}<$ 2.7; see Table 3).

When the stories described novel situations, participants relied, not surprisingly, on the information in the texts. Readers overall took longer to read "inaccurate" outcomes than to read "accurate" outcomes, which, on its own, would suggest that the narratives generally biased the readers to expect "accurate" outcomes. However, the obtained interaction indicated that this occurred for "unambiguous" rather than for "suspenseful" contexts; "unambiguous" contexts led to strong expectations for "accurate" outcomes, whereas "suspenseful" contexts did not bias a particular expectation. In fact, the observed interaction was largely driven by long reading times in the "unambiguous-inaccurate" condition; the content of these stories primed expectations for an outcome, the opposite of which took place. In contrast, "suspenseful" contexts engendered uncertainty or at least failed to encourage strong beliefs for particular story outcomes. ${ }^{5}$ There was also little evidence for a spillover effect in Experiment 3; previously, this effect was taken as modest evidence for the application of prior knowledge following inaccurate information.

An additional element of this pattern is worthy of note. Consider that the novel stories in Experiment 3 were unfamiliar, in contrast to the well-known historical events presented in Experiments 1 and 2. Overall, outcome reading times differed across the three experiments [a betweensubjects ANOVA: $F_{1}(2,118)=4.323, M S_{\mathrm{e}}=401,380, p<$ $\left..05 ; F_{2}(2,58)=19.037, M S_{\mathrm{e}}=44,296, p<.001\right]$. Specifically, reading times in Experiment $3(M=3,230 \mathrm{msec})$ were longer than those obtained in Experiment $1(M=$ $2,976 \mathrm{msec})\left[F_{1}(1,59)=5.150, M S_{\mathrm{e}}=773,729, p<.05\right.$;
$\left.F_{2}(1,29)=15.131, M S_{\mathrm{e}}=124,945, p<.001\right]$ and Experiment $2(M=2,899 \mathrm{msec})\left[F_{1}(1,59)=6.690, M S_{\mathrm{e}}=\right.$ $941,410, p<.05 ; F_{2}(1,29)=26.444, M S_{\mathrm{e}}=114,745, p<$ $.001]$, with no difference between Experiments 1 and 2 (both $F$ s $<1$ ). These results suggest an influence of prior knowledge on reading speed (given that the lengths of the sentences across experiments were comparable). Similar effects of reading speed based on familiarity have been obtained in studies examining narrative (Graesser, Singer, \& Trabasso, 1994) and metaphor (e.g., Blasko \& Briihl, 1997) comprehension. Prior knowledge likely enhances reading fluency by providing the necessary background, if retrieved, for encoding story information.

\section{GENERAL DISCUSSION}

The goal of this study was to investigate the influence of prior knowledge on readers' comprehension of incorrect information during moment-by-moment reading. Previous work suggested that readers may fail to notice and act on discrepancies between what they know and what texts tell them, potentially relying on obviously inaccurate sources. Determining the conditions under which readers fall victim to faulty information is important for determining the contributions of both prior knowledge and unfolding text content to comprehension processes and products. But to date, these comprehension failures have typically been examined using product-oriented measures, including recall and verification tasks, collected after reading has been completed. If such failures are not observed during reading, these effects might be due to task demands or retrieval difficulties, rather than to online processes of knowledge activation or integration.

In Experiment 1, participants overall exhibited reading slowdowns when stories contained inaccurate historical outcomes. However, these slowdowns were attenuated if suspenseful contexts suggested that the inaccurate outcomes were plausible. Participants appeared to notice information discrepant with their prior knowledge during reading, but their noticing was influenced by the nature of the text content. In Experiment 2, prior knowledge use was encouraged with a preactivation task preceding each story. The pattern of reading latencies resembled that for Experiment 1; the preactivation task conferred no additional benefit on readers' processing of the texts. In Experiment 3, participants read stories with unfamiliar topics to make prior knowledge irrelevant for integrating the outcome sentence with the unfolding discourse. Story contexts now solely guided their expectations for events.

Overall, these results suggest several important conclusions. First, prior knowledge influences readers' considerations of inaccurate information, although these considerations are also reflective of story contexts. Although it is perhaps not surprising that both prior knowledge and discourse information influence comprehension, this study shows that even strongly held knowledge can be subtly influenced by text descriptions. Second, these sources exert an interactive impact during readers' processing of texts. Moment-by-moment reading is influenced by what readers already know but can be 
shaped, even with respect to well-worn knowledge, by what texts tell them. Third, although the difficulty readers experienced with false information was reduced by story contexts, the locus of these effects was focused around the incorrect information. The spillover effects suggest that, for well-known facts such as those tested in these experiments, readers quickly return to relying on their prior knowledge as texts unfold. Finally, reading times proved useful for assessing readers' moment-by-moment reliance on prior knowledge. Besides indicating difficulties with textual inaccuracies, participants take longer to read outcomes (e.g., Experiment 3) when they cannot rely on prior knowledge.

Readers' moment-by-moment processing, thus, was directly influenced by what they already knew. Surprisingly, though, the preactivation task in Experiment 2 failed to bolster participants' reliance on prior knowledge in such a way that they were no longer influenced by story contexts. These types of tasks are designed to help readers activate potentially appropriate concepts but need not lead to a reduction in the activation of other, competing concepts (McNamara \& McDaniel, 2004), including those suggested by suspenseful story contexts. Previous work has similarly shown that various types of prior warnings fail to reduce participants' reliance on inaccurate text information (e.g., Gerrig, 1989). Of course, an additional possibility for the failure of these tasks is that they require readers to activate prior knowledge only before reading, and in no way encourage them to do so during or after reading has been completed (but see Marsh \& Fazio, 2006). Readers, in general, may not spontaneously rely on prior knowledge or engage in evaluative processing with respect to text descriptions, unless specifically prompted to do so (McKoon \& Ratcliff, 1989, 1992).

This issue - the degree to which comprehension activities and their concomitant concepts are relied on as a function of tasks and text content - has been of critical importance in accounts of reading and, more generally, discourse comprehension (e.g., Linderholm \& van den Broek, 2002; Magliano \& Radvansky, 2001; van den Broek, Rapp, \& Kendeou, 2005). Although almost all models of text processing have shared the view that readers' prior knowledge, text content, and task goals are crucial for comprehension (e.g., Rapp \& van den Broek, 2005), they have tended to treat these contributors as either equivalently informative or subordinate to the role of prior knowledge. In addition, these models have largely focused on the ways in which readers attempt to build coherent representations in memory, with relatively little consideration as to the validity of the sources that inform those representations. An interesting set of questions concerns the ways in which tasks and content influence readers' beliefs about the information sources they consider and how critically they might evaluate them. There is some precedent for this work in the extant literature: Consider that recall tasks may place a greater emphasis on what was recently read, rather than on prior knowledge, whereas online validation tasks may place an emphasis on careful evaluation utilizing prior knowledge (Egidi \& Gerrig,
2006; Rapp \& Kendeou, 2007). In fact, these findings may explain why readers, when tested with postreading measures, entrust recently read, inaccurate information more so than seems appropriate. The degree to which tasks encourage readers to rely more or less on story contexts and prior knowledge may determine the ways in which these sources influence processing (e.g., Singer, 2006; Singer \& Halldorson, 1996; Singer et al., 1992).

Despite the expectations potentially biased by story contexts, readers in the present study appeared to take notice of discrepancies as they related to actual historic facts. It is worth noting that because half of the texts included factual errors, this may have encouraged vigilance on the part of the readers to notice these inaccuracies. Future work could vary the proportion of accurate to inaccurate information in texts, to determine whether readers' expectations about content might mediate such noticing. Of course, noticing and acting upon discrepancies are two different activities (e.g., Cook, Guéraud, Was, \& O'Brien, 2007; Cook \& Myers, 2004; Otero \& Kintsch, 1992; Seifert, 2002). Work on memory updating suggests that although readers may notice inconsistencies, this does not guarantee that they will, in response, revise what they know in order to reconcile differences (Rapp \& Kendeou, 2007, in press). In some situations, individuals fail to update what they know; in others, individuals update but, rather than incorporating those revisions into memory, compartmentalize them to suggest their appropriateness only with respect to the current material or experience (e.g., Gerrig \& Prentice, 1991; O’Brien, Rizzella, Albrecht, \& Halleran, 1998; Potts \& Peterson, 1985; Potts, St. John, \& Kirson, 1989). Again, task demands and reader strategies have been invoked as critical components in determining whether readers act upon discrepancies and, if they do, how they deal with such content (van den Broek et al., 2005).

It is worth noting that the study of how readers contend with inaccurate information has not just theoretical implications, but practical ones as well. Researchers examining conceptual change in educational settings have articulated the need for texts that help students revise what they know by targeting and refuting their misconceptions (e.g., Alvermann \& Hague, 1989; Diakidoy \& Kendeou, 2001; Guzzetti, Williams, Skeels, \& Wu, 1997; Hynd \& Alvermann, 1986; Maria \& MacGinitie, 1987). If students fail to incorporate these refutations into prior knowledge, the result may be a continued reliance on inaccurate misconceptions. The present project is, in some sense, a twist on this issue, investigating cases in which readers presumably know what is correct but encounter texts in which information is inaccurate. Hopefully, for these cases, readers do not revise what they know; after all, it would not be useful for readers to come to believe that George Washington was not actually the first president of the United States. These situations also differ from cases in which readers might be unsure as to the accuracy of what they are reading. To fully understand the role of prior knowledge, we need to know when readers rely on what they know and when they do not, as well as when they update their prior knowledge and when they fail to do 
so (e.g., McNamara, Kintsch, Songer, \& Kintsch, 1996; Rapp \& Kendeou, 2007). A more elaborated description of reader processing will help assess whether readers are generally susceptible to the influence of texts or whether such susceptibility depends on particular reading variables (Green \& Brock, 2002), both during reading and after reading is completed. These types of findings may prove useful in the development of interventions designed to foster learning in cases that involve conceptual change or, more generally, necessitate evaluative processing during reading (Rapp, van den Broek, McMaster, Kendeou, \& Espin, 2007).

A growing body of literature continues to investigate the ways in which individuals recruit prior knowledge to comprehend discourse experiences. Understanding the conditions under which readers might deny or rely on the incorrect information they encounter not only can provide direct insight into what prior knowledge contributes to the reading process, but also can help outline the particular factors that may lead to comprehension failures. These accounts can only enhance our understanding of the ways in which readers contend with the blends of accurate and incorrect information they read.

\section{AUTHOR NOTE}

This article is based on work supported by Institute of Education Sciences Grant R305G040021 and a Faculty Summer Fellowship from the Office of the Dean of the Graduate School at the University of Minnesota. I am grateful to Richard Gerrig, Sid Horton, Panayiota Kendeou, and Daniel Slaten for their helpful comments as the project unfolded; Mike Mensink, Laura Potter, and Janette Wilsey for their assistance in data collection; and Emily Durbin for advice on data analysis. I also thank Danielle McNamara, Henry Roediger, Elizabeth Stine-Morrow, and three anonymous reviewers for their comments on an earlier draft. Please address correspondence to D. N. Rapp, School of Education and Social Policy and Department of Psychology, Northwestern University, 2120 Campus Drive, Evanston, IL 60208 (e-mail: rapp@northwestern.edu).

\section{REFERENCES}

Albrecht, J. E., \& O'Brien, E. J. (1993). Updating a mental model: Maintaining both local and global coherence. Journal of Experimental Psychology: Learning, Memory, \& Cognition, 19, 1061-1069.

AlvermanN, D. E., \& Hague, S. A. (1989). Comprehension of counterintuitive science text: Effects of prior knowledge and text structure. Journal of Educational Research, 82, 197-202.

Alvermann, D. E., \& Hynd, C. (1989). Effects of prior knowledge activation modes and text structure on nonscience majors' comprehension of physics. Journal of Educational Research, 83, 97-102.

Anderson, R. C., \& Pichert, J. W. (1978). Recall of previously unrecallable information following a shift in perspective. Journal of Verbal Learning \& Verbal Behavior, 17, 1-12.

Bartlett, F. C. (1932). Remembering: A study in experimental and social psychology. Cambridge: Cambridge University Press.

BLASKO, D. G., \& BRIIHL, D. S. (1997). Reading and recall of metaphorical sentences: Effects of familiarity and context. Metaphor \& Symbol, 12, 261-285

Bower, G. H., Black, J. B., \& Turner, T. J. (1979). Scripts in memory for texts. Cognitive Psychology, 11, 177-220.

BRANSFORD, J. D., \& Johnson, M. K. (1972). Contextual prerequisites for understanding: Some investigations of comprehension and recall. Journal of Verbal Learning \& Verbal Behavior, 11, 717-726.

BREWER, W. F. (1996). The nature of narrative suspense and the problem of rereading. In P. Vorderer, H. J. Wulff, \& M. Friedrichsen (Eds.), Suspense: Conceptualizations, theoretical analyses, and empirical explorations (pp. 107-127). Mahwah, NJ: Erlbaum.
Chiesi, H., SPILICH, G. J., \& Voss, J. F. (1979). Acquisition of domainrelated information in relation to high and low domain knowledge. Journal of Verbal Learning \& Verbal Behavior, 18, 257-274.

CooK, A. E., \& GuÉraud, S. (2005). What have we been missing? The role of general world knowledge in discourse processing. Discourse Processes, 39, 265-278.

Cook, A. E., Guéraud, S., Was, C. A., \& O'Brien, E. J. (2007). Foregrounding effects during reading, revisited. Discourse Processes, 44, 91-111.

Cook, A. E., Halleran, J. G., \& O'Brien, E. J. (1998). What is readily available during reading? A memory-based view of text processing. Discourse Processes, 26, 109-129.

Cook, A. E., \& Myers, J. L. (2004). Processing discourse roles in scripted narratives: The influences of context and world knowledge. Journal of Memory \& Language, 50, 268-288.

Diakidoy, I. N., \& KendeOU, P. (2001). Facilitating conceptual change in astronomy: A comparison of the effectiveness of two instructional approaches. Learning \& Instruction, 11, 1-20.

EGIDI, G., \& GERRIG, R. J. (2006). Readers' experiences of characters' goals and actions. Journal of Experimental Psychology: Learning, Memory, \& Cognition, 32, 1322-1329.

Ferreira, F., \& Clifton, C. (1986). The independence of syntactic processing. Journal of Memory \& Language, 25, 348-368.

Garrod, S., \& Terras, M. (2000). The contribution of lexical and situational knowledge to resolving discourse roles: Bonding and resolution. Journal of Memory \& Language, 42, 526-544.

GERRIG, R. J. (1989). Suspense in the absence of uncertainty. Journal of Memory \& Language, 28, 633-648.

GERRIG, R. J. (1993). Experiencing narrative worlds. New Haven, CT: Yale University Press.

Gerrig, R. J., \& Prentice, D. A. (1991). The representation of fictional information. Psychological Science, 2, 336-340.

Gick, M. L., \& HolyoAK, K. J. (1983). Schema induction and analogical transfer. Cognitive Psychology, 15, 1-38.

Gilbert, D. T., Krull, D. S., \& Malone, P. S. (1990). Unbelieving the unbelievable: Some problems in the rejection of false information. Journal of Personality \& Social Psychology, 59, 601-613.

Gilbert, D. T., Tafarodi, R. W., \& Malone, P. S. (1993). You can't not believe everything you read. Journal of Personality \& Social Psychology, 65, 221-233.

Graesser, A. C., Singer, M., \& Trabasso, T. (1994). Constructing inferences during narrative comprehension. Psychological Review, 101, 371-395.

Green, M. C., \& BRock, T. C. (2002). In the mind's eye: Transportationimagery model of narrative persuasion. In M. C. Green, J. J. Strange, \& T. C. Brock (Eds.), Narrative impact: Social and cognitive foundations (pp. 315-341). Mahwah, NJ: Erlbaum.

Guzzetti, B. J., Snyder, T. E., Glass, G. V., \& Gamas, W. S. (1993). Promoting conceptual change in science: A comparative meta-analysis of instructional interventions from reading education and science education. Reading Research Quarterly, 28, 117-159.

Guzzetti, B. J., Williams, W. O., Skeels, S. A., \& Wu, S. M. (1997). Influence of text structure on learning counterintuitive physics concepts. Journal of Research in Science Teaching, 34, 701-719.

Halldorson, M., \& Singer, M. (2002). Inference processes: Integrating relevant knowledge and text information. Discourse Processes, 34, 145-161.

Hynd, C., \& Alvermann, D. E. (1986). The role of refutation text in overcoming difficulty with science concepts. Journal of Reading, 29, 440-446.

Kendeou, P., Rapp, D. N., \& Van den Broek, P. (2003). The influence of readers' prior knowledge on text comprehension and learning from text. In R. Nata (Ed.), Progress in education (pp. 189-209). New York: Nova.

KendeOU, P., \& VAN den BRoeK, P. (2007). The effects of prior knowledge and text structure on comprehension processes during reading of scientific texts. Memory \& Cognition, 35, 1567-1577.

KInTSCH, W. (1988). The role of knowledge in discourse comprehension: A construction-integration model. Psychological Review, 95, 163-182.

KInTSCH, W. (1998). Comprehension: A paradigm for cognition. Cambridge: Cambridge University Press.

Lea, R. B., Mulligan, E. J., \& Walton, J. L. (2005). Accessing dis- 
tant premise information: How memory feeds reasoning. Journal of Experimental Psychology: Learning, Memory, \& Cognition, 31, 387-395.

Linderholm, T., \& VAN DEN BRoEK, P. (2002). The effects of reading purpose and working memory capacity on the processing of expository text. Journal of Educational Psychology, 94, 778-784.

Long, D. L., Wilson, J., Hurley, R., \& Prat, C. S. (2006). Assessing text representations with recognition: The interaction of domain knowledge and text coherence. Journal of Experimental Psychology: Learning, Memory, \& Cognition, 32, 816-827.

Magliano, J. P., \& Radvansky, G. A. (2001). Goal coordination in narrative comprehension. Psychonomic Bulletin \& Review, 8, 372-376.

Maria, K., \& MacGinitie, W. (1987). Learning from texts that refute the reader's prior knowledge. Reading Research \& Instruction, 26, 222-238.

MARsh, E. J., \& FAZIO, L. K. (2006). Learning errors from fiction: Difficulties in reducing reliance on fictional stories. Memory \& Cognition, 34, 1140-1149.

Marsh, E. J., Meade, M. L., \& Roediger, H. L., III (2003). Learning facts from fiction. Journal of Memory \& Language, 49, 519-536.

McCullough, D. (2005). 1776. New York: Simon \& Schuster.

McKoon, G., \& RATCLIFF, R. (1989). Inferences about contextually defined categories. Journal of Experimental Psychology: Learning, Memory, \& Cognition, 15, 1134-1146.

McKoon, G., \& Ratcliff, R. (1990). Textual inferences: Models and measures. In D. A. Balota, G. B. Flores d'Arcais, \& K. Rayner (Eds.), Comprehension processes in reading (pp. 403-422). Hillsdale, NJ: Erlbaum.

McKoon, G., \& Ratcliff, R. (1992). Inference during reading. Psychological Review, 99, 440-466.

McNamara, D. S., \& Kintsch, W. (1996). Learning from text: Effects of prior knowledge and text coherence. Discourse Processes, 22, 247-287.

McNamara, D. S., Kintsch, E., Songer, N. B., \& Kintsch, W. (1996). Are good texts always better? Interactions of text coherence, background knowledge, and levels of understanding in learning from text. Cognition \& Instruction, 14, 1-43.

McNamara, D. S., \& McDaniel, M. A. (2004). Suppressing irrelevant information: Knowledge activation or inhibition? Journal of Experimental Psychology: Learning, Memory, \& Cognition, 30, 465-482.

Morris, R. K. (1994). Lexical and message-level sentence context effects on fixation times in reading. Journal of Experimental Psychology: Learning, Memory, \& Cognition, 20, 92-103.

Nelson, T. O., \& NARENS, L. (1980). Norms of 300 general-information questions: Accuracy of recall, latency of recall, and feeling-of-knowing ratings. Journal of Verbal Learning \& Verbal Behavior, 19, 338-368.

O'Brien, E. J., Rizzella, M. L., Albrecht, J. E., \& Halleran, J. G. (1998). Updating a situation model: A memory-based text processing view. Journal of Experimental Psychology: Learning, Memory, \& Cognition, 24, 1200-1210.

Otero, J., \& Kintsch, W. (1992). Failures to detect contradictions in a text: What readers believe versus what they read. Psychological Science, 3, 229-235.

Pearson, P. D., Hansen, J., \& Gordon, C. (1979). The effect of background knowledge on young children's comprehension of explicit and implicit information. Journal of Reading Behavior, 11, 201-209.

Potts, G. R., \& Peterson, S. B. (1985). Incorporation versus compartmentalization in memory for discourse. Journal of Memory \& Language, 24, 107-118.

Potts, G. R., ST. John, M. F., \& Kirson, D. (1989). Incorporating new information into existing world knowledge. Cognitive Psychology, 21, 303-333.

Prentice, D. A., Gerrig, R. J., \& Bailis, D. S. (1997). What readers bring to the processing of fictional texts. Psychonomic Bulletin \& Review, 4, 416-420.

RAPP, D. N., \& GERRIG, R. J. (2002). Readers' reality-driven and plotdriven analyses in narrative comprehension. Memory \& Cognition, 30, 779-788.

RAPP, D. N., \& Gerrig, R. J. (2006). Predilections for narrative outcomes: The impact of story contexts and reader preferences. Journal of Memory \& Language, 54, 54-67.

Rapp, D. N., Gerrig, R. J., \& Prentice, D. A. (2001). Readers' trait- based models of characters in narrative comprehension. Journal of Memory \& Language, 45, 737-750.

RAPP, D. N., \& KENDEOU, P. (2007). Revising what readers know: Updating text representations during narrative comprehension. Memory \& Cognition, 35, 2019-2032.

RAPP, D. N., \& KendeOU, P. (in press). Noticing and revising discrepancies as texts unfold. Discourse Processes.

Rapp, D. N., \& VAN DEN BroeK, P. (2005). Dynamic text comprehension: An integrative view of reading. Current Directions in Psychological Science, 14, 276-279.

Rapp, D. N., van den Broek, P., McMaster, K. L., Kendeou, P., \& EsPIN, C. A. (2007). Higher-order comprehension processes in struggling readers: A perspective for research and intervention. Scientific Studies of Reading, 11, 289-312.

Rizzella, M. L., \& O'Brien, E. J. (2002). Retrieval of concepts in script-based texts and narratives: The influence of general world knowledge. Journal of Experimental Psychology: Learning, Memory, \& Cognition, 28, 780-790.

Schank, R. C., \& Abelson, R. P. (1977). Scripts, plans, goals, and understanding: An inquiry into human knowledge structures. Hillsdale, NJ: Erlbaum.

SEIFERT, C. M. (2002). The continued influence of misinformation in memory: What makes a correction effective? In B. H. Ross (Ed.), The psychology of learning and motivation: Advances in research and theory (Vol. 41, pp. 265-292). San Diego: Academic Press.

SINGER, M. (2006). Verification of text ideas during reading. Journal of Memory \& Language, 54, 574-591.

Singer, M., \& Halldorson, M. (1996). Constructing and validating motive bridging inferences. Cognitive Psychology, 30, 1-38.

Singer, M., Halldorson, M., Lear, J. C., \& Andrusiak, P. (1992). Validation of causal bridging inferences in discourse understanding. Journal of Memory \& Language, 31, 507-524.

SpIREs, H. A., \& Donley, J. (1998). Prior knowledge activation: Inducing engagement with informational texts. Journal of Educational Psychology, 90, 249-260.

Sulin, R. A., \& Dooling, D. J. (1974). Intrusion of a thematic idea in retention of prose. Journal of Experimental Psychology, 103, 255-262.

Trueswell, J. C., Tanenhaus, M. K., \& Garnsey, S. (1994). Semantic influences on parsing: Use of thematic role information in syntactic ambiguity resolution. Journal of Memory \& Language, 33, 285-318.

VAN den Broek, P., Rapp, D. N., \& Kendeou, P. (2005). Integrating memory-based and constructionist processes in accounts of reading comprehension. Discourse Processes, 39, 299-316.

Wheeler, S. C., Green, M. C., \& Brock, T. C. (1999). Fictional narratives change beliefs: Replications of Prentice, Gerrig, and Bailis (1997) with mixed corroboration. Psychonomic Bulletin \& Review, 6, 136-141.

ZWAAN, R. A. (1994). Effect of genre expectations on text comprehension. Journal of Experimental Psychology: Learning, Memory, \& Cognition, 20, 920-933.

\section{NOTES}

1. Some conceptualizations of prior knowledge include phonemic, morphemic, syntactic, and pragmatic or social knowledge as critical components to the generation and application of mental representations for language comprehension. Although these elements no doubt contribute to readers' comprehension of text, the examination of prior knowledge here is restricted to the investigation of semantic or factual knowledge.

2. Overall, outcomes that included not or never were longer than outcomes without them: Negated outcomes contained, on average, 10.94 words $(S D=1.63)$, and nonnegated outcomes contained, on average, 9.53 words $(S D=1.76)[t(31)=15.94, p<.001]$. When measured by number of characters, negated outcomes contained, on average, 62 characters $(S D=9.33)$, and nonnegated outcomes contained, on average, 57 characters $(S D=9.74)[t(31)=11.80, p<.001]$. Importantly, though, negation was counterbalanced across outcome conditions, so that negated accurate outcomes $(M=10.81$ words, $S D=1.68 ; M=61.69$ characters, $S D=9.40)$ and negated inaccurate outcomes ( $M=11.06$ words, $S D=$ $1.61 ; M=62.38$ characters, $S D=9.55$ ) did not differ on measures of length, and neither did nonnegated accurate outcomes ( $M=9.81$ words, $S D=1.72 ; M=58.31$ characters, $S D=9.80)$ and nonnegated inac- 
curate outcomes ( $M=9.25$ words, $S D=1.81 ; M=55.75$ characters, $S D=9.82)$ (both $t \mathrm{~s}<1.5$ ). Although negated sentences were overall longer, recall that they conveyed accurate and inaccurate outcomes in equivalent proportions to each other and to nonnegated sentences.

3 . The participants were not instructed as to whether the stories described fictional or historical events but, simply, that they would be reading brief texts. Of course, over the course of the experiment, the participants may have come to believe that they were reading texts that were historical, fictional, or some combination thereof. The present project did not focus on the influence of these types of beliefs on processing (e.g., Zwaan, 1994), although such work is worthy of investigation to further understand the types of prior knowledge that can be brought to bear on reading experiences (Gerrig, 1989).

4. To compare the findings in Experiments 1 and 2 more directly, an explicit statistical comparison was conducted using a 2 (story context: unambiguous vs. suspenseful) $\times 2$ (outcome sentence: historically accurate vs. inaccurate) ANOVA with experiment (1 vs. 2) as a betweensubjects variable. Recall that the stimuli were identical across the two experiments, with the only change involving prior knowledge activation preceding each story in Experiment 2. If the patterns of data obtained in the two experiments were similar, we would expect little in the way of a between-subjects effect. The omnibus ANOVA obtained a main effect of context $\left[F_{1}(1,118)=260.176, M S_{\mathrm{e}}=186,888, p<.001 ; F_{2}(1,58)=\right.$ $\left.119.252, M S_{\mathrm{e}}=199,339, p<.001\right]$ and an interaction between context and outcome $\left[F_{1}(1,118)=13.953, M S_{\mathrm{c}}=154,846, p<.001 ; F_{2}(1,58)=\right.$ $\left.11.852, M S_{\mathrm{e}}=81,563, p<.005\right]$. But most important for this analysis, there was no interaction as a function of experiment and no other main effects (all $F$ s $<2.3$ ). These results suggest that the experimental findings were similar. This null result should be interpreted with caution, of course, but is informative given that the two experiments employed the same number of participants, the same stimuli, and similar methodologies (besides the prior knowledge manipulation). I thank the reviewers for suggesting this comparison.

5. Experiment 3 was intended to show that by reducing the utility of prior knowledge, suspense would invoke clear uncertainty for particular story outcomes. This is in contrast to Experiment 1 (and 2), in which suspense reduced but did not obviate outcome certainty, given readers' prior knowledge. One way to quantitatively assess whether this effect was differentially reduced across Experiments 1 and 3 is to compare the difference in reading times between accurate and inaccurate outcomes following suspenseful (and "suspenseful") contexts as a function of experiment. A one-way ANOVA compared this difference between Experiments 1 and 3, obtaining a significant effect $\left[F_{1}(1,58)=14.487, M S_{\mathrm{e}}=260,250\right.$, $\left.p<.001 ; F_{2}(1,58)=11.853, M S_{\mathrm{e}}=162,434, p<.005\right]$. In other words, the difference in reading times between accurate and inaccurate outcomes was larger in Experiment 1 (i.e., $410 \mathrm{msec}$ ) than was the difference in reading times between "accurate" and "inaccurate" outcomes in Experiment 3 (i.e., $45 \mathrm{msec}$ ). This finding further confirms the notion that suspense effects can be moderated by relevant (or a lack of) prior knowledge. I thank the reviewers for suggesting this type of comparison.

(Manuscript received June 21, 2007;

revision accepted for publication October 28, 2007.) 